\title{
Increasing efficiency of equipment work for preliminary separation of non-ferrous metals
}

\author{
V. Ya. Potapov *, A.I. Afanasyev, V. V. Potapov, D. S. Stozhkov, and A. A. Chirkova \\ Ural State Mining University, 620144, Ekaterinburg, Russia
}

\begin{abstract}
The article provides an overview of the methods for pre-sorting sulfide ores, as well as the design of separators for implementing these methods. The practical prospects of the use of radioresonance and X-ray fluorescence separation for the preliminary preparation of sulfide ores are shown. The use of not one, but two or more different physical properties of the separated ore components during radiometric beneficiation opens up additional possibilities in increasing the selectivity of this process and expanding the scope of its application. It is proposed to reduce the energy intensity of crushing processes, due to the impact on the rock electrical breakdown of ore in order to reduce its strength. In this case, the processes of crushing and grinding are replaced by processes of selective destruction along the boundaries of inclusions of the useful component. The substantiation of the technology for the separation of poor copper-zinc ores is presented. The relationship of sulfide content and electrical breakdown voltage is shown. The results of experiments in determination the specific energy consumption for the electrical processing of lean ore, depending on the sulfide content, are presented. The principle is substantiated, and a simulation model of the separation process is developed. The block diagram of the separation process algorithm is given.A description of the methodology for working with software is done. The energy costs of a new technology for the separation of poor sulfide ores are determined.
\end{abstract}

\section{Introduction}

Relevance. Improving the efficiency of equipment during ore processing is possible with the improvement of technological and energy indicators of the working process, which imposes certain restrictions when choosing a method of preliminary ore separation.

Preliminary sorting of ore is intended:

- for preliminary enrichment, which allows to reduce up to $50 \%$ the volume of ore supplied to crushing and grinding [1]. For poor ores, this decrease in volume is substantially greater.

- for a preliminary separation of a complex mineral composition of minerals into separate components processed according to various schemes.

- to obtain lump concentrates, which are then sent to pyrometallurgical processes.

\footnotetext{
* Corresponding author: valentin.potapov@m.ursmu.ru
} 


\section{Materials and Methods}

Object of study. Separators for the separation of non-ferrous metal ores.

Purpose of the study. Improving the efficiency of equipment for preliminary separation and destruction of sulfide ores.

Research Methods. Methods of mathematical and physical modeling, mathematical statistics during experimental research on a semi-industrial installation.

Research methodology. General logical methods (analysis and synthesis of scientific, technical and patent information, induction, synthesis, etc.), similarity theory.

\section{Research results and discussion}

Preliminary sorting of ore is carried out by various types of separators.

Optical separators separate ores by color and particle shape. The principle of their work is the reflection of light by minerals [2] with different intensities. In our country, these separators were developed in the sixties of the last century $[3,4,5]$.

At the end of the last century, Gunsons Sortex Ltd photometric separators were widely used $[6,7]$. They enriched the material with a particle size of $150+3 \mathrm{~mm}$. In these separators, the intensity of the reflected light was measured with the free fall of the pieces. Removing pieces is done with compressed air. Maximum air valve response rate for material less than $20 \mathrm{~mm} 200 \mathrm{~Hz}$.

The disadvantage of these separators is that if the mineral is located inside the piece, then the air valve will not operate and the conditioned piece will fall into the tails.

In radio resonance separators, high-frequency electromagnetic radiation of the radio wave range is used $[8,9]$. The most widespread was the capacitive radio-resonance separator, which turned out to be more efficient and promising [10].

Induction and capacitive radio-resonance methods for the enrichment of non-ferrous metal ores have shown high efficiency [11]. Separation parameters for a particular type of ore should be determined on the basis of special studies. These studies were carried out on sulfide ores (fineness class $-50+10 \mathrm{~mm}$ ) having a specific electrical resistance of $10-6 \ldots$ 10-2 Ohm $\bullet \mathrm{m}$, and rock-forming minerals (quartz, calcite, mica, etc.) $-10+12 \ldots 10+16$ $\mathrm{Ohm} \cdot \mathrm{m}[12]$. The ores were separated on a single-channel belt separator B-75 with an induction feed-through sensor.

These studies, as well as the work carried out in the 80s at USMU, showed the practical prospects of using radio-resonance separation for preliminary preparation of sulfide ores. The accuracy of the information is ensured by an appropriate number of sensors.

This method is characterized by the influence of abnormally rich pieces on closely spaced poor ones, which leads to a decrease in productivity due to the need to increase the intervals between pieces.

Luminescent separators can be used to separate certain types of ores. Not all minerals possess luminescence. The reason for the luminescence of minerals is the presence of impurities in them - uranium, rare earth elements, manganese, chromium, rubidium and other metals. Iron, nickel, and others can attenuate luminescence [13].

$\mathrm{X}$-ray fluorescence separators are used to enrich non-ferrous, ferrous and rare metals and non-metallic minerals [14]. Their production is carried out by RADOS LLC, Integra company, EGONT LLC and others. Currently, several types of two- and three-product X-ray radiometric separators SRF2-300, SRF3-300, SRF4-150, SRF4-50, etc. are produced. covering a range of ore fineness from 10 to $300 \mathrm{~mm}$.

The principle of their operation is based on measuring the spectral characteristics of the secondary characteristic x-ray radiation. A separation parameter is formed on the spectrum of these characteristics. It allows you to identify pieces of individual elements and their 
quantitative content. Separators produced by various companies differ in the organization of power flows, particle removal methods, and the design of measuring systems. The main disadvantage inherent in X-ray fluorescence separators is the inability to identify the mineral that is inside the piece.

As a result of the analysis of physical processes arising from the interaction of pieces of rock with radiation, several properties appear that are suitable for radiometric enrichment. For electromagnetic radiation of the radio wave range, such properties are electrical conductivity, permittivity and magnetic susceptibility.

The use of not one, but two or more different physical properties of the separated ore components during radiometric beneficiation opens up additional possibilities in increasing the selectivity of this process and expanding the scope of its application. This work was carried out on complex sulfide-scheelite ores. [20].

A number of scientists dealt with the problems of resource and energy conservation: V.I. Revnivtsev, V.A. Chanturia in the second half of the 20th century proposed reducing the energy consumption of crushing processes by affecting the rock in order to reduce its strength. In this case, the processes of crushing and grinding are replaced by processes of selective destruction along the boundaries of inclusions of the useful component. The most effective is the fracture process due to the development of tensile stresses at the interspersed boundaries. Such effects are: thermal exposure, treatment with a high-frequency electromagnetic field, magnetic pulse processing, electric ore breakdown [16, 17, 18-25].

Our studies have shown that, electrical breakdown of ore is most effective in the processing of sulfide ores.

The studies were carried out on the poor copper-zinc ore of the Youth deposit with a mass fraction: chalcopyrite $-1,4 \ldots 2,5 \%$; tennantitis- $0,1 \ldots 0,2 \%$; sphalerite $-0,7 \ldots 1,7 \%$; pyrite $-22,8 \ldots 34,2 \%$; waste rock $61,4 \ldots 75 \%$. The rich copper-zinc ore of this deposit contains the same components, but with different mass fractions. The rich ore of this deposit contains up to $87 \%$ sulfides.

With the currently accepted technologies for the enrichment of copper-zinc ores, up to $50 \%$ sulfides are found in the tailings. If you reduce the sulfide content in the tailings to $30 \%$, then the volumes of processed ore and, accordingly, energy consumption will increase significantly, but at the same time, the loss of minerals will decrease. Therefore, the limit value of the sulfide content in the tailings should be determined by economic calculation.

As a result of the experiments, we found that the specific breakdown voltage $(\mathrm{Uy}, \mathrm{V} / \mathrm{cm})$ depends on the sulfide content, with a content $(\alpha, \mathrm{g} / \mathrm{g}$ ) of sulfides $0,3 \mathrm{~g} / \mathrm{g}$ is $540 \mathrm{~V} / \mathrm{cm}$, at $\alpha=0,4 \mathrm{~g} / \mathrm{g}-\mathrm{Uy}=107 \mathrm{~V} / \mathrm{cm}$, with $\alpha=0,5 \mathrm{~g} / \mathrm{g}-\mathrm{Uy}=56 \mathrm{~V} / \mathrm{cm}$, with $\alpha=0,6 \mathrm{~g} / \mathrm{g}-\mathrm{Uy}$ $=10 \mathrm{~V} / \mathrm{cm}$. The dependence of the specific breakdown voltage on the sulfide content is exponential.

Experiments have shown that electrical (thermal) breakdown can be taken as the main feature for separation. To determine the costs of thermal breakdown, the voltage and current in the secondary winding of the transformer, as well as its time, were measured. It was found that the magnitude of the current in the secondary winding depends on the sulfide content, the flow time is hundredths of a second.

The dependence of the specific energy intensity (Ey, $\mathrm{kJ} / \mathrm{kg}$ ) of the process of electric processing of poor sulfide ore from the boundary sulfide content has the form:

$$
\ln E_{y}=5,6-13,4 x
$$

The correlation relation of equation (1) $\left.\mathrm{R}^{2}=0,99[19,20]\right)$ indicates the presence of a close relationship between the boundary content of sulfides and specific energy consumption for electrical processing. Equation (1) is adequate when $\alpha$ changes from 0,1 to $0,4 \mathrm{~g} / \mathrm{g}$.

Equation 1 shows that a decrease in the boundary sulfide content leads to an increase in energy consumption for electric processing, since a decrease in the sulfide content leads to 
an increase in breakdown voltage. Accordingly, with a constant current flow time, the power necessary for breaking pieces increases. It was found that the energy consumption for the electric processing of ore pieces at $[\alpha]=0,3 \mathrm{~g} / \mathrm{g}$ is $1,35 \mathrm{~kW} * \mathrm{~h} / \mathrm{t}$ and decreases with increasing boundary content.

The separation algorithm is shown in Figure 1.

Equipment performing this process includes an X-ray fluorescence separator equipped with an additional sensor, which simultaneously serves as a softening device. It receives pieces of rock mass, which the X-ray fluorescence separator recognized as waste rock. If in these pieces there is a certain amount of mineral, then thermal breakdown occurs (with simultaneous softening) and the piece is sent for further processing.

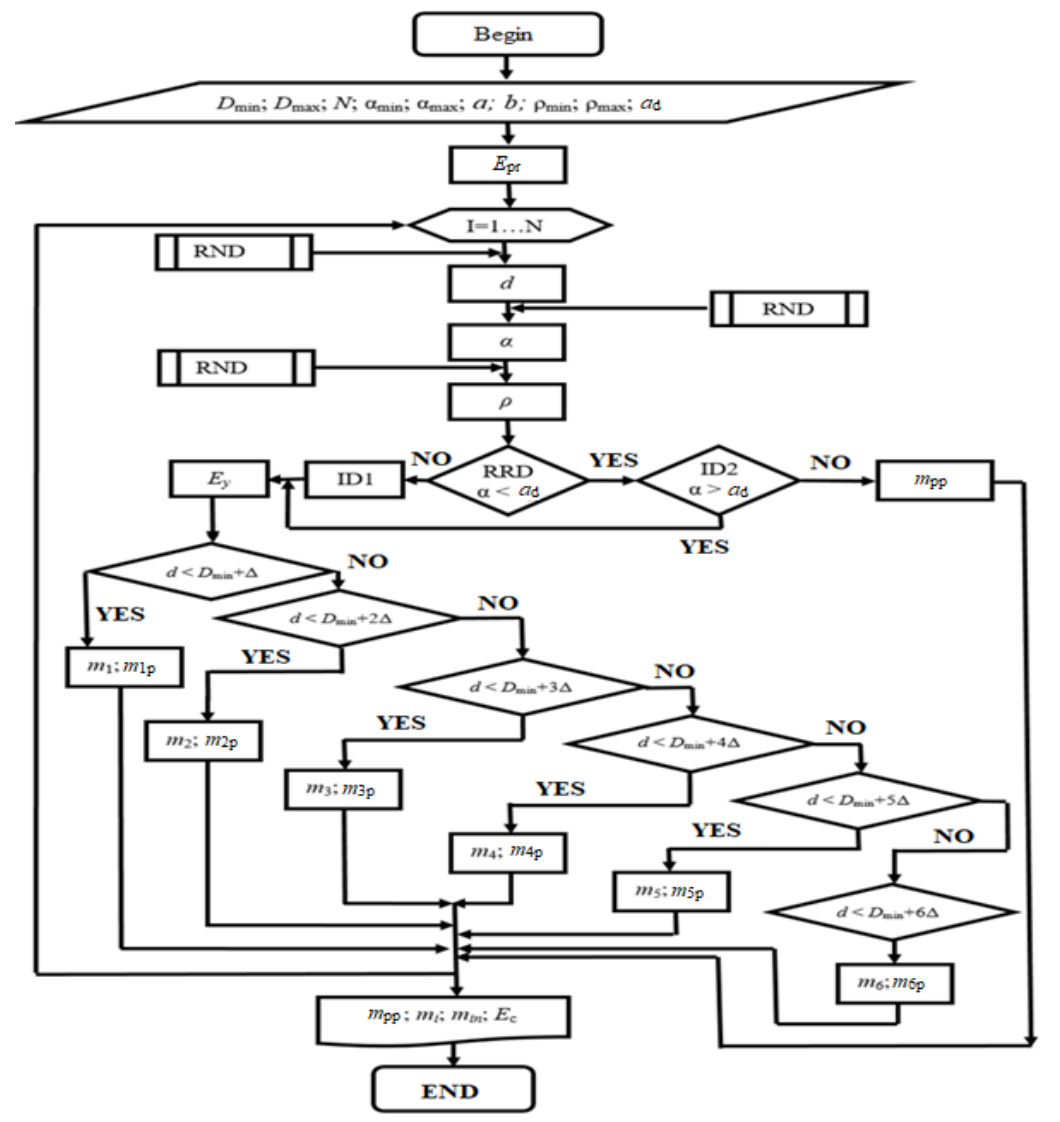

Fig. 1. Block diagram of the separation process algorithm.

The model contains blocks:

1. Input data: Minimum $d_{\min }$ and maximum $d_{\max }$ piece size, mm. Parameters of the law of distribution of $a$ and $b$ sizes of pieces. The maximum $\alpha_{\max }$, average $\alpha_{a v}$ and admissible $[\alpha]$ (boundary) sulfide content. 3. Maximum $\rho_{\max }$ and minimum $\rho_{\min }$ rock mass density, the number of pieces $N$ of rock mass.

2. Calculation of process parameters: Specific energy consumption $\left(E_{\mathrm{oy}}, \mathrm{kJ} / \mathrm{kg}\right)$ for electrical processing of rock mass. Equivalent piece diameter $\left(d_{i}\right)$. The density of the piece is $\rho_{i}$. Equivalent piece diameter $d$. Mass $(\mathrm{kg})$ of a piece of ore $m_{i p}$.

3. Identification of a piece with a sulfide content greater than the boundary. If the sulfide content in the piece is greater than the boundary, then the breakdown of the rock occurs and 
the piece is sent for crushing by impact. Pieces with a mineral content less than the boundary are sent to the second sensor.

4. The second identification of the piece missed by the first sensor. If the sulfide content in the piece is greater than the boundary, then the breakdown of the rock occurs and the piece is sent to crushing by impact

5. Determination of the mass of waste rock, ore and sulfides.

6. The energy of destruction of a piece of ore by impact and the specific energy consumption are determined.

In ore with a sulfide content of more than $0,6 \mathrm{~g} / \mathrm{g}$, it is advisable to accept a permissible (boundary) content of at least $0,3 \mathrm{~g} / \mathrm{g}$. Up to $90 \%$ of the total ore mass will go into the tailings, which will significantly reduce the costs of its further processing.

It has been established that the energy consumption for crushing punched pieces of offbalance ore subjected to electric processing is reduced by $1,1 \ldots 1,6$ times, and the degree of grinding [21] of ore $(i)$ in a ball mill increases almost 1,5 times. At the same time, the output of small classes increases significantly (by $15 \ldots 18 \%$ ) and the output of the class $+5 \mathrm{~mm}$ decreases (by 25 ... 28\%).

The dependence of the total energy consumption for electric processing, crushing and grinding of poor sulfide ore was determined

$$
\ln E_{c}=1,33-0,72[\alpha]
$$

where $[\alpha]$ is the boundary (permissible) content of sulfides, $g / g$.

The relatively large correlation relation of equation (2) $R^{2}=0,96$ [20]) indicates the presence of a significant relationship between the boundary sulfide content and the total energy consumption.

When using the radio-resonance method for sulphide ore dressing, the tailings yield will be $42 \%$, and the total energy consumption $11,3 \mathrm{~kW} * \mathrm{~h} / \mathrm{t}$. The proposed method of preenrichment allows due to the softening of sulfides to significantly reduce energy consumption compared with radio-resonance.

An increase in the yield of the finished class by 1,2 times is equivalent to a reduction in grinding time and, all other things being equal, a corresponding reduction in energy consumption.

\section{Conclusions}

1. Preliminary sorting of sulfide ores leads to a reduction in grinding time and an increase in the yield of small classes.

2. An increase in the boundary content of sulfides leads to a decrease in the energy intensity of the electric processing process by $1,2 \ldots 1,7$ times, compared with the X-ray fluorescence separation method.

\section{References}

1. V. A. Mokrousov, V. A. Lileev, Radiometric concentration of non-radioactive ores (Nedra, Moscow, 1979)

2. A. N. Platonov, The nature of the coloring of minerals (Naukova Dumka, Kiev, 1976).

3. I. I. Kreindlin, R. A. Markova, L. M. Paska, Instruments for radiometric ore dressing (Atomizdat, Moscow, 1972)

4. I. T. Stop, S. D. Yurchenko, A. K. Voitenko, Non-ferrous metals, 8, 67 (1973)

5. V. I. Revnivtsev, Non-ferrous metals, 5, 25 (1969) 
6. V. I. Aniskin, L. A. Mishina., V. P. Murugov, Machines for sorting agricultural products by color (Mashinostroenie, Moscow, 1972)

7. M. I. Malanyin, A. P. Krupenina, M. M. Cherkashina, Enrichment of diamond-bearing bedrock and sand (Gosgeoltekh-izdat, Moscow, 1961)

8. K. Okazaki, Technology of ceramic dielectrics (Energy, Moscow, 1976)

9. I. I. Kreindlin, R. A. Markova, L. M. Paska, Instruments for radiometric ore dressing (Atomizdat, Moscow, 1972)

10. G. R. Nosov, V. P. Chernyshev, I. F. Zaitsev, Mineral processing. Rep. inter. scientific and technical collection, 5, 95 (1966)

11. V. I. Revnivtsev, Improvement of ore preparation, 3 (1980)

12. N. V. Melnikova, V. V. Rzhevsky, M. M. Protodyakonova, Physical properties of rocks (Nedra, Moscow, 1975)

13. V. I. Revnivtsev, T. G. Rybakova, E. P. Leman, X-ray radiometric concentration of complex ores of non-ferrous and rare metals (Nedra, Moscow, 1990)

14. V. V. Zverev, Ore dressing, 1, 18 (1984)

15. V. I. Revnivtsev, G. V. Gaponov, L. G. Zagorsky, Selective destruction of minerals (Nedra, Moscow, 1988)

16. V. A. Chanturia, Mining Journal, 2, 2 (2007)

17. S. L. McGill, J. W. Walkiewicz, G. A. Smyres, Proc. Materials Res. Soc. SMPM, Reno, 124, 247 (1988)

18. K. E. Haque, Symposium on gold metallurgy. Winnipeg, Canada, 327 (1987)

19. V. A. Lileev, V. V. Zverev, V. N. Gulin, Non-ferrous metals, 12, 88 (1978)

20. V. A. Mokrousov, V. A. Lileev, I. D. Gurov, Non-ferrous metals, 5, 64 (1973)

21. P. P. Ananiev, S. A. Goncharov, I. A. Tangaev, Energy intensity of the processes of extraction and processing of minerals (Nedra, Moscow, 1986)

22. V. V. Rzhevsky, Yu. I. Protasov, Electric destruction of rocks (Nedra, Moscow, 1972)

23. M. A. Emelin, V. N. Morozov, N. P. Novikov, New methods of rock destruction: Textbook for High Schools (Nedra, Moscow, 1990)

24. A. K. Mitropolsky, Technique of statistical research (Nauka, Moscow, 1971)

25. O. S. Bogdanova, Preparatory processes (Nedra, Moscow,1982)

26. V. Ya. Potapov, A. I. Afanasev, V. V. Potapov, D. S. Stozhkov, V.A. Trop, GIAB, 9, 55 (2019) 